\begin{tabular}{|c|c|c|c|}
\hline \multirow{3}{*}{$\begin{array}{r}\text { Case Reports in } \\
\text { Gastroenterology }\end{array}$} & Case Rep Gastroenterol 2017; & & \multirow[b]{2}{*}{ Oparger } \\
\hline & $\begin{array}{l}\text { DOI: 10.1159/000479311 } \\
\text { Publisned online: September 26, } 2017\end{array}$ & $\begin{array}{l}\text { (c) } 2017 \text { The Author(s) } \\
\text { Published by S. Karger AG, Basel } \\
\text { www.karger.com/crg }\end{array}$ & \\
\hline & $\begin{array}{l}\text { This article is licensed under the } \mathrm{Cr} \\
\text { International License (CC BY-NC) (ht } \\
\text { Usage and distribution for commercial }\end{array}$ & $\begin{array}{l}\text { nons Attribution-NonCommercial } 4 . \\
\text { ger.com/Services/OpenAccessLicense } \\
\text { uires written permission. }\end{array}$ & \\
\hline
\end{tabular}

\title{
Unusual Clinical Presentation of Hemobilia with Recurrent Vasovagal Episodes
}

\author{
Abhinav Tiwari $^{\mathrm{a}}$ Tariq Hammad $^{\mathrm{b}}$ Himani Sharma $^{\mathrm{a}}$ \\ Khola Qamar $^{\mathrm{b}} \quad$ Mohammad Saud Khan $^{\mathrm{a}}$ Zubair Khan $^{\mathrm{a}}$ Ali Nawras \\ Thomas Sodeman ${ }^{\mathrm{b}}$ \\ ${ }^{a}$ Department of Internal Medicine, University of Toledo Medical Center, Toledo, $\mathrm{OH}_{1} \mathrm{USA}_{i}$ \\ ${ }^{b}$ Department of Gastroenterology, University of Toledo Medical Center, Toledo, $\mathrm{OH}$, USA
}

\section{Keywords}

Hemobilia · Recurrent vasovagal episodes · Laparoscopic cholecystectomy

\begin{abstract}
Hemobilia is caused by the abnormal connection between a blood vessel and the bile duct, which is usually iatrogenic and caused by hepatobiliary procedures. The classic triad of hemobilia includes biliary colic, obstructive jaundice, and gastrointestinal bleeding. We present the case of an 80-year-old man who had laparoscopic cholecystectomy complicated by hemobilia. He had an unusual presentation of hemobilia in the form of transient vasovagal episodes in addition to abdominal pain and hematochezia.

(C) 2017 The Author(s) Published by S. Karger AG, Basel
\end{abstract}

\section{Introduction}

Hemobilia (HB) is defined as hemorrhage into the biliary tract from an aberrant connection between a blood vessel and the bile duct [1]. With the increasing use of invasive procedures that involve the biliary tract, iatrogenic trauma has become the predominant etiology of HB. Iatrogenic trauma can occur with liver biopsy, transhepatic cholangiography, and transhepatic drainage or during hepatobiliary surgeries, including laparoscopic cholecystec- 
Tiwari et al.: Unusual Clinical Presentation of Hemobilia with Recurrent Vasovagal Episodes

tomy. The classic triad of HB, although present in $<40 \%$ of cases, includes biliary colic, obstructive jaundice, and gastrointestinal bleeding $[1,2]$. Minor HB is usually asymptomatic; however, arterial HB can have a dramatic presentation, presenting as acute blood loss and biliary obstruction due to the formation of occlusive blood clots in the biliary tree. HB can have a delayed presentation, up to weeks or months after the inciting causal event. Blood clots in the biliary tree can masquerade as stones, causing cholangitis, pancreatitis, and cholecystitis. The innervation of the biliary tract is through sympathetic fibers originating from T7 through T10 as well as parasympathetic fibers from both vagal nerves. The manipulation or distention of the biliary tree can trigger a vagal response, which manifests as bradycardia and hypotension $[3,4]$. Esophagogastroduodenoscopy (EGD) is the diagnostic modality of choice for HB, as it can demonstrate blood flow from the major duodenal papilla, in addition to excluding other causes of hemorrhage.

Here, we present the case of a patient who presented with recurrent episodes of gastrointestinal bleeding, biliary colic, and vasovagal attacks. In this case, rapid bleeding into the bile duct caused transient vagal stimulation which manifested as bradycardia and hypotension.

\section{Case Presentation}

An 80-year-old male with a past medical history of coronary artery disease presented to the emergency department with acute-onset epigastric pain. Two months prior to this acute presentation, he had common bile duct (CBD) stone removal and laparoscopic cholecystectomy performed for choledocholithiasis. Epigastric pain that had started $4 \mathrm{~h}$ earlier was $6 / 10$ in intensity and sharp in nature with no radiation. He was hemodynamically stable with a temperature of $97.4^{\circ} \mathrm{F}$, blood pressure (BP) of $134 / 76 \mathrm{~mm} \mathrm{Hg}$, and heart rate (HR) of $90 / \mathrm{min}$. He denied having any nausea, vomiting, or diarrhea. During the further evaluation, his BP suddenly dropped to $80 / 60 \mathrm{~mm} \mathrm{Hg}$, and his HR plunged to $50 / \mathrm{min}$. This trend continued for $10 \mathrm{~min}$, and as preparation was started to give intravenous fluids, he had $1 \mathrm{epi}$ sode of hematochezia. A few minutes later, his BP and HR promptly increased to 128/78 mm $\mathrm{Hg}$ and $89 / \mathrm{min}$, respectively, with mild improvement in his abdominal pain. His laboratory workup was unremarkable, except for hemoglobin of $9.6 \mathrm{gm} / \mathrm{dL}$ from a baseline of around $11 \mathrm{gm} / \mathrm{dL}$. He was transferred to the intensive care unit and was given intravenous pantoprazole. The gastroenterology team was consulted, and an emergent EGD was performed, which was normal with no stigmata of bleeding. He also received a colonoscopy that was also normal with no source of bleeding. On the 2nd hospital day, he had a second episode of sudden, unexplained drop in BP and HR lasting about $8 \mathrm{~min}$. This event was again followed by an episode of hematochezia and then by restoration of BP and HR back to normal. He was managed conservatively with fluid resuscitation and transfusion of packed red blood cells. He was discharged home in the next few days, as the repeat EGD failed to show any evidence or location of bleeding. One month later, he presented again with a similar triad of epigastric pain, transient hypotension, and bradycardia followed by hematemesis. Epigastric pain, hypotension, and bradycardia were transient and resolved after the episode of hematochezia. Antegrade deep small bowel enteroscopy failed to localize the source of bleeding. On the next day, an emergent EGD, performed after the patient had a bout of hematemesis, revealed fresh blood in the stomach and a blood clot adherent to the duodenal papilla. Liver function tests performed at that time also revealed total bilirubin of $2.3 \mathrm{~g} / \mathrm{dL}$, direct bilirubin of 1.3 $\mathrm{g} / \mathrm{dL}$, AST $26 \mathrm{U} / \mathrm{L}$, ALT $28 \mathrm{U} / \mathrm{L}$, and alkaline phosphatase $156 \mathrm{U} / \mathrm{L}$. A clot adhering to the 
Tiwari et al.: Unusual Clinical Presentation of Hemobilia with Recurrent Vasovagal Episodes

duodenal papilla raised suspicion for $\mathrm{HB}$, which was plausible given the history of recent cholecystectomy. Tagged red blood cell scan demonstrated a blush of activity in the region of the proximal duodenum. CT angiography revealed active bleeding in the lateral segment of the left hepatic lobe arising from the left hepatic artery, suggesting a pseudoaneurysm (Fig. 1). Vascular surgery was consulted, and the patient underwent embolization of the hepatic artery (Fig. 2). At the 2-month follow-up, the patient had not experienced any further episodes of hematochezia, melena, epigastric pain, or episodic hypotension/bradycardia.

\section{Discussion}

A laparoscopic cholecystectomy is reportedly associated with a $0.2-1 \%$ incidence of biliary and vascular injuries [5]. Such injuries may manifest in the early postoperative period or may present as late as 120 days after the procedure [6]. Our patient presented 60 days later. Hemorrhage into the biliary tract from an aberrant connection between a blood vessel and bile duct leads to HB. Hepatic artery aneurysm and liver trauma are known to be the most common causes of this pathologic vascular-biliary connection [7-9]. There has been an increase in iatrogenic causes of $\mathrm{HB}$ in recent years, with rates varying from $1 \%$ with liver biopsy [10] or $4 \%$ with transhepatic cholangiography [11] to $14 \%$ with transhepatic drainage [12] and 40-85\% during hepatobiliary surgeries [8, 13, 14]. In our case, pseudoaneurysm of the hepatic artery was a complication of the laparoscopic cholecystectomy that was done 2 months earlier. Typically, HB causes melena or acute upper gastrointestinal bleeding, and patients may experience acute biliary pain from distention of the bile ducts [15]. In 1871, Quincke [16] described a case of HB, stressing the classical clinical a triad of biliary colic, jaundice, and gastrointestinal bleeding; however, this triad is present in $<40 \%$ of the cases $[1,2]$. HB was the cause of epigastric pain in our patient, as the pain was transient and each time resolved after an episode of gastrointestinal bleeding. The repeated vasovagal episodes experienced by our patient can be explained by reviewing the innervation of the biliary tree. The neural supply to the biliary tract includes vagal efferent nerves releasing acetylcholine, sympathetic fibers releasing norepinephrine, and sensory nerves containing Substance P. Sensory fibers influence the neural response, acting via the vagus through central reflexes [4]. There have been reports suggesting that CBD manipulation during surgery triggers vasovagal episodes, resulting in bradycardia and hypotension [3]. VanSonnenberg et al. [17] reported 5 cases of percutaneous cholecystostomy, during which the patients suffered profound vagal reactions with severe hypotension and bradycardia during the procedure. This was due to vagal stimulation caused by manipulation of the bile ducts, an effect that was blunted by administration of atropine and dopamine. In our case, rapid bleeding into the biliary tract caused distention of the CBD, thus triggering the parasympathetic neurons leading to a vasovagal episode, manifesting as bradycardia and hypotension. Vagal stimulation can cause (1) inhibition of sympathetic activity, which can lead to symptomatic hypotension, and (2) increased parasympathetic activity, which may manifest by sinus bradycardia. In our case, each symptomatic episode terminated once the bile duct was cleared of blood. Liver function tests were mildly elevated and were consistent with obstruction due to blood clots in the CBD, leading to mild cholestasis. A painful stimulus is another plausible explanation of these vagal episodes in our patient. However, he had few episodes of vagal stimulation during active HB, even in the absence of pain. In the past, he has had multiple admissions to our hospital for abdominal and thoracic pain, which were unrelated to bile duct disease, but he never had vasovagal episodes with such painful episodes. Therefore, the 
Tiwari et al.: Unusual Clinical Presentation of Hemobilia with Recurrent Vasovagal Episodes

vasovagal episodes were uniquely associated with HB in our patient. Typically, vasovagal episodes are short in duration, lasting 1-2 min; therefore, they may go unrecognized in some patients. It is prudent to mention that HB is a challenging diagnosis, and high index of suspicion should be maintained if there is a history of invasive instrumentation near the hepatobiliary area.

In conclusion, this is a case of unusual clinical presentation of $\mathrm{HB}$, which presented with a transient vasovagal attack in addition to the more widely recognized triad of biliary colic, jaundice, and gastrointestinal bleeding.

\section{Statement of Ethics}

Approval from an ethics committee was not required in this case, as this is a case report. We have obtained informed consent from the patient to publish this report.

\section{Disclosure Statement}

The authors have no relevant financial or nonfinancial relationships to disclose.

\section{References}

1 Sandblom P: Hemobilia (Biliary Tract Hemorrhage): History, Pathology, Diagnosis, Treatment. Springfield, IL, Charles C, Thomas, 1972.

2 Golich J, Rilinger N, Brado M, Huppert P, Vogel J, Siech M, et al: Non-operative management of arterial liver hemorrhages. Eur Radiol 1999;9:85-88.

- 3 Vallakati A, Reddy M, Olayee M, Lakkireddy D: Cardiac arrest from asystole during endoscopic retrograde cholangiopancreatography: a rare but fatal complication. J Atr Fibrillation 2013;6:938.

$4 \quad$ Mawe GM: Advances in the neurophysiology of the gallbladder. Commun Soil Sci Plant Anal 1992;1008:181.

5 Connor S, Garden OJ: Bile duct injury in the era of laparoscopic cholecystectomy. Br J Surg 2006;93:158-168.

6 Balsara KP, Dubash C, Shah CR: Pseudoaneurysm of the hepatic artery along with common bile duct injury following laparoscopic cholecystectomy. A report of two cases. Surg Endosc 1998;12:276-277.

7 Yoshida J, Donahue PE, Nyhus LM: Hemobilia review of recent experience with a worldwide problem. Am J Gastroenterol 1987;82:448-453.

Green MHA, Duell RM, Johnson CD, Jamieson NV: Haemobilia. Br J Surg 2002;88:773-786.

9 Glisson F: Anatomia Hepatis, ed 1. Amsterdam, Janssonium and Weyerstraten, 1654 . Gastroenterology 1977;72:941-944.

-11 Cahow CE, Burrell M, Greco R: Hemobilia following percutaneous transhepatic cholangiography. Am Surg 1977;185:235-241.

12 Monden M, Okamura J, Kobayashi N, Shibata N, Horikawa S, Fujinmoto T, et al: Hemobilia after percutaneous transhepatic biliary drainage. Arch Surg 1980;115:161-164.

13 Otah E, Cushin BJ, Rozenblit GN, Neff R, Otah KE, Cooperman AM: Visceral artery pseudoaneurysms following pancreatoduodenectomy. Arch Surg 2002;137:55-59.

14 Hofmann AF: Bile acids: the good, the bad, and the ugly. News Physiol Sci 1999;14:24-29.

15 Baillie J: Hemobilia. Gastroenterol Hepatol (NY) 2012;8:270-272.

16 Quincke H: Ein Fall von Aneurysma der Leberarterie. Klin Wochenschr 1871;88:773-786.

17 vanSonnenberg E, Wing VW, Pollard JW, Casola G: Life-threatening vagal reactions associated with percutaneous cholecystostomy. Radiology 1984;151:377-380. 
Tiwari et al.: Unusual Clinical Presentation of Hemobilia with Recurrent Vasovagal Episodes

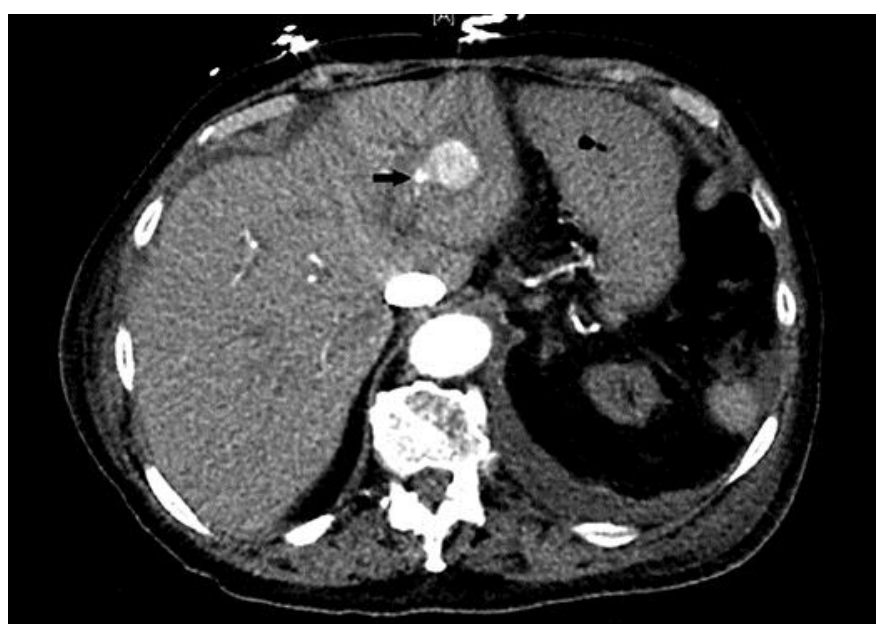

Fig. 1. CT angiography of the abdomen and pelvis showing an area of contrast extravasation in the lateral segment of the left hepatic lobe lying close to a branch of the left hepatic artery (arrow), suggesting active bleeding from a pseudoaneurysm.

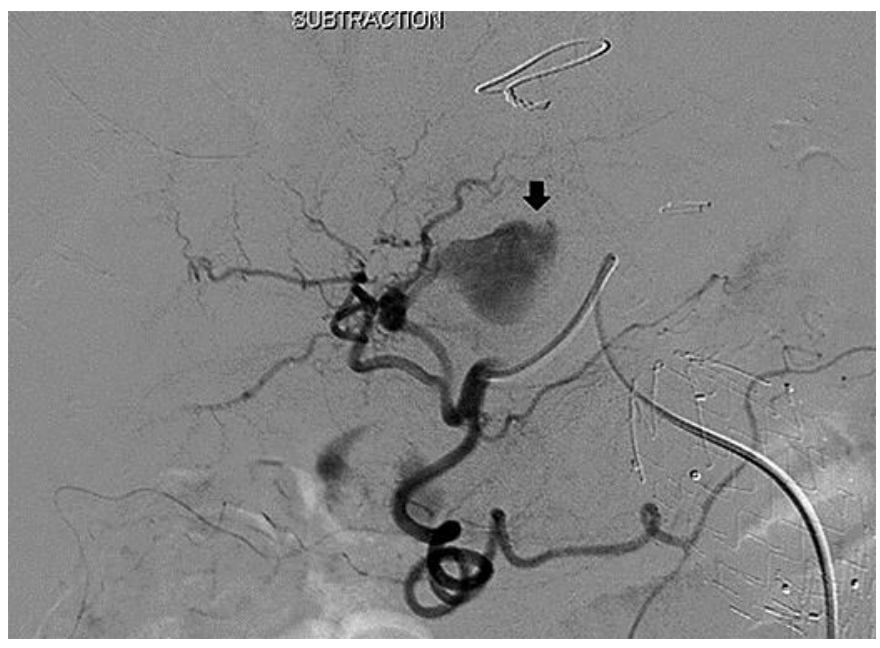

Fig. 2. Fluoroscopic guided peripheral intervention of the left hepatic artery showing active contrast leak (arrow). 